\title{
Randomised controlled trial of simulation-based education for mechanical cardiopulmonary resuscitation training
}

\author{
Andrew R Coggins, ${ }^{\oplus 1,2}$ Cameron Nottingham ${ }^{2}$ Karen Byth, ${ }^{2}$ Kevin R Ho, ${ }^{2}$ \\ Felicia A Aulia, ${ }^{1}$ Margaret Murphy, ${ }^{1}$ Amith L Shetty, ${ }^{1,2}$ Anna Todd ${ }_{1}{ }^{3}$ Nathan Moore ${ }^{2,4}$
}

${ }^{1}$ Emergency Department, Westmead Hospital, Sydney, New South Wales, Australia ${ }^{2}$ Western Clinical School, University of Sydney, Sydney, New South Wales, Australia ${ }^{3}$ Sydney Clinical Skills and Simulation Centre (SCSSC), Royal North Shore Hospital, Saint Leonards, New South Wales, Australia

${ }^{4}$ Simulated Learning

Environment for Clinical Training (SiLECT), Westmead Hospital, Sydney, New South Wales, Australia

\section{Correspondence to}

Dr Andrew R Coggins, Emergency Medicine, NSW Health, Syndey, NSW 2151, Australia;

andrew.coggins@health.nsw. gov.au

Received 29 December 2017 Revised 2 January 2019 Accepted 22 March 2019 Published Online First 2 April 2019

\section{Linked}

- http://dx.doi.org/10.1136/ emermed-2017-207384 - http://dx.doi.org/10.1136/ emermed-2018-208087

Check for updates

(C) Author(s) (or their employer(s)) 2019. No commercial re-use. See rights and permissions. Published by BMJ.

To cite: Coggins AR,

Nottingham C, Byth K,

et al. Emerg Med $J$

2019:36:266-272

\begin{abstract}
Introduction Mechanical cardiopulmonary

resuscitation (M-CPR) is increasingly used in the management of cardiac arrest. There are no previously reported randomised studies investigating M-CPR training. This study of newly trained M-CPR providers hypothesised that a brief simulation-based intervention after 4 months would improve M-CPR performance at 6 months.

Methods This study used a simulated 'in situ' cardiac arrest model. The M-CPR device used was a proprietary Lund University Cardiac Assist System 3 machine (Physio Control, Redmond, Washington, USA). Standardised baseline training was provided to all participants. Following training, baseline performance was assessed. The primary outcome measure was the time taken to initiate M-CPR and the secondary outcome was performance against a checklist of errors. Participants were then randomised to intervention group (simulation training) or control group (routine clinical use of M-CPR). After 6 months the outcome measures were reassessed. Comparative statistical tests used an intention-to-treat analysis.
\end{abstract}

Results 112 participants were enrolled. The intervention group $(n=60)$ and control group $(n=52)$ had similar demographic characteristics. At the 6-month assessment, median time to M-CPR initiation was $27.0 \mathrm{~s}$ (IQR 22.0-31.0) in the intervention group and 31.0s (IQR 25.6-46.0) in the control group $(p=0.003)$. The intervention group demonstrated fewer errors compared with controls at 6 months $(p<0.001)$

Conclusion In this randomised study of approaches to $\mathrm{M}-\mathrm{CPR}$ training, providers receiving additional simulation-based training had higher retention levels of M-CPR skills. Therefore, when resuscitation skills are newly learnt, provision follow-up training should be an important consideration.

\section{BACKGROUND}

The two most influential predictors of mortality in cardiac arrest are provision of effective basic life support (BLS) and early defibrillation. ${ }^{1}$ Overall patient outcomes are determined by various factors, including the quality of cardiopulmonary resuscitation (CPR), public education, access to defibrillators and well-trained providers. ${ }^{2}$ Mechanical CPR (M-CPR) devices can be used to deliver uninterrupted chest compressions with the caveat that its use can lead to significant BLS interruptions. M-CPR devices are increasingly used in EDs despite

\section{Key messages}

What is already known on this subject

- Mechanical cardiopulmonary resuscitation (M-CPR) is being increasingly adopted in the management of refractory cardiac arrest.

- The best approach to M-CPR training is unknown, but it is well-established that newly acquired resuscitation skills decline significantly within a few months of baseline training.

- The requirement for reliable and rapid deployment of M-CPR devices in the ED represents a current challenge for resuscitation educators.

What this study adds

- In this randomised controlled trial of approaches to M-CPR training, the intervention group received a brief simulation-based 'refresher' 4 months after baseline training.

- At a 6-month assessment of performance, providers receiving an additional brief simulation intervention had a significantly shorter time to initiate M-CPR compared with control subjects.

- Serial simulation-based skills training appears to be an effective strategy for the maintenance of M-CPR skills.

- A similar educational approach may also be worthy of consideration in training for other occasionally used resuscitation skills.

a paucity of supporting evidence. ${ }^{3} 4$ However, M-CPR may be desirable in specific circumstances such as prolonged resuscitation, during patient transport and as a bridge to emergency invasive procedures such as extracorporeal membrane oxygenation (ECMO). ${ }^{4-7}$

An increasing uptake of M-CPR represents a challenge for resuscitation educators. Published reports showing interruptions to effective BLS occur when applying M-CPR highlight the importance of education and training. ${ }^{89}$ A previous observational study of M-CPR training describes a steep 'learning curve' and outlines an approach using a dedicated team. ${ }^{10}$ In this study, the team approach described resulted in a reduction in the time to initiate $\mathrm{M}-\mathrm{CPR} .^{10}$

To date, there have been no randomised trials examining M-CPR training or the role of simulation in this context. Therefore, we undertook a 
randomised controlled trial (RCT) of serial simulation-based training at an ED with no previous use of M-CPR. Our null hypothesis was that ' $M-C P R$ providers exposed to a brief standardised simulation 4 months following baseline training would have similar M-CPR performance at 6 months when compared with control subjects receiving identical baseline training and routine clinical exposure'.

\section{MATERIALS AND METHODS}

The study was completed between 1 December 2016 and 31 May 2017 and adhered to the Australian National Statement on Ethical Conduct in Human Research.

Due to the paucity of data for M-CPR, the evidence related to other ALS skills was extrapolated to predict performance following training. ${ }^{11}{ }^{12}$ Studies of ALS skills retention have shown that performance degrades as early as 3 months. ${ }^{13}$ Therefore, we anticipated that new M-CPR skills would decline between 3 and 6 months following training. The primary outcome measure selected was 'the time to effective M-CPR application at an assessment of performance 6 months following standardised baseline training'.

\section{Power calculation}

A previous pilot study with another proprietary M-CPR device suggested that the primary outcome measure (time required to initiate M-CPR) would exhibit a skewed distribution. The sample size calculation was therefore based on a Mann-Whitney rank-sum test of the null hypothesis $\mathrm{H}_{0}: \operatorname{Pr}(C>I)=0.5$ versus an alternative $\mathrm{H}_{1}: \operatorname{Pr}(C>I) \sim=0.5$, where $C$ is a randomly selected observation from the control group and $I$ is a randomly selected observation from the intervention group. The statistical programme $n$ Query was used to calculate that 50 subjects in each group would have $80 \%$ power to detect a probability of 0.66 that an observation in the control group is greater than an observation in the intervention group using a Mann-Whitney rank-sum test with a $5 \%$ two-sided significance level. ${ }^{14} \mathrm{~A}$ total sample size of 112 subjects was chosen to allow for an expected participant drop-out rate of $10 \%$.

\section{Inclusion criteria}

Predefined inclusion criteria were that participants must be 'trained ALS providers' and able to 'provide written informed consent'. Exclusion criteria were that participants were 'untrained in $A L S$ ', had 'prior M-CPR training' or were 'unable to complete envisaged follow-up'.

\section{Study setting and equipment}

The setting for the study was Westmead Hospital, a university affiliated tertiary centre. An ED 'in situ' simulation model was selected for training and assessment. We used a low-fidelity simulation manikin (Laerdal, Stavanger, Norway) with a modification of $7 \mathrm{~cm}$ of high-density foam under the synthetic chest skin covering. The simulated model was considered superior to a clinical study due to logistics, a requirement of precision measurements and for reliable standardisation of the simulated scenario. The device used in this study was a proprietary Lund University Cardiac Assist System (LUCAS-3) device (Physio Control, Redmond, Washington, USA). All LUCAS devices deliver compressions via a battery powered piston mechanism. ${ }^{15}$ The LUCAS device has no defined maximum or minimum weight limit, but its use is often constrained by extremes of chest girth (either too small or too large). The simulation manikin

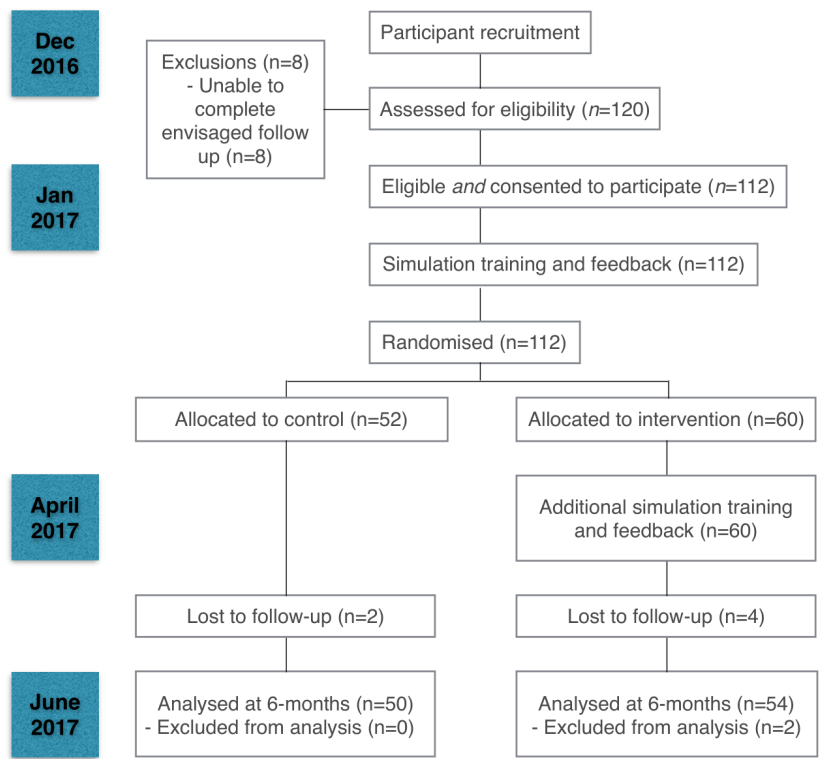

Figure 1 Flow diagram of enrolment, randomisation and training of participants.

used in this study represented a typical adult male, with a weight of $80 \mathrm{~kg}$ and chest circumference of $93 \mathrm{~cm}$.

\section{Training and assessment}

At enrolment, baseline training was delivered to interdisciplinary participants allocated to pairs on an ad hoc basis. Working in pairs was considered necessary to create a real-life representation of M-CPR deployment. The standardised training consisted of an instructional video followed by a brief M-CPR simulation scenario. ${ }^{16}$ The training video was devised using the device manufacturer's user manual. Following the video, the participants immediately received $4 \mathrm{~min}$ of facilitated 'hands-on' time with the M-CPR device. The video and 'hands-on' time were only provided once (at baseline training). Subsequently, the participants were asked to complete the standardised simulation with assessment of the time to initiate M-CPR $(6 \mathrm{~min})$ followed by semi-structured feedback $(4 \mathrm{~min}) .{ }^{16}$

After 6 months, available participants completed their final assessment (figure 1). Participants were timetabled for follow-up within predefined time windows (figure 1). At the 6-month assessment, the participants were assigned a working partner from the same randomisation group. However, they were not necessarily allocated with their previous partner due to the constraints of rostering and the limited time windows available in which to complete assessments.

\section{Standardised simulation}

Participants were given scripted instructions asking them to 'prepare to deploy the M-CPR device in a timely manner following the paramedic handover' (figure 2). After $90 \mathrm{~s}$ of preparation time, a scripted handover was read to participants by the simulated paramedic actor. The timing clock was started at the end of the handover. Following successful initiation of M-CPR, participants were asked to 'continue two cycles of ALS' including integration of defibrillation and drug administration. The postscenario feedback was delivered by facilitators trained in simulation-based medical education and was time limited 


\begin{tabular}{|c|c|c|}
\hline & Simulation Notes & Results \\
\hline Handover & $\begin{array}{l}\text { For simulation assessment allow } 90 \text { seconds } \\
\text { preparation time with LUCAS device. } \\
\text { (The timer is started when handover is completed by } \\
\text { simulation faculty 'paramedic) }\end{array}$ & $\begin{array}{c}\text { Time }=0: 00 \\
\text { (start stopwatch) }\end{array}$ \\
\hline $\begin{array}{l}\text { First Mechanical CPR } \\
\text { compression? } \\
\text { (PRIMARY OUTCOME) }\end{array}$ & $\begin{array}{l}\text { Defined as 'the measured time from the end of } \\
\text { handover until the first effective compression by the } \\
\text { LUCAS device' (See checklist of errors) }\end{array}$ & Time to first compression: \\
\hline & $\begin{array}{c}\text { Checklist } \\
\text { (List of Critical Errors) }\end{array}$ & $\begin{array}{c}\text { Completion of task on first attempt? } \\
\text { (please circle) }\end{array}$ \\
\hline \multicolumn{2}{|c|}{ 1) Lift patient to semi-sitting or log-roll? (30 degrees semi-sitting preferred) } & $\begin{array}{l}\text { Correct at first attempt } \\
\text { Incorrect on first attempt }\end{array}$ \\
\hline \multicolumn{2}{|c|}{ Risk of accidental removal of Tube? (e.g. ETT tube was not secured) } & $\begin{array}{l}\text { Correct at first attempt } \\
\text { Incorrect on first attempt }\end{array}$ \\
\hline \multicolumn{2}{|c|}{ 3) Correct position of suction cup? } & $\begin{array}{l}\text { Correct at first attempt } \\
\text { Incorrect on first attempt }\end{array}$ \\
\hline \multicolumn{2}{|c|}{ 4) Arms are outside device? (for the simulation can go above head) } & $\begin{array}{l}\text { Correct at first attempt } \\
\text { Incorrect on first attempt }\end{array}$ \\
\hline \multicolumn{2}{|c|}{ 5) Device locked in correctly on first attempt? } & $\begin{array}{l}\text { Correct at first attempt } \\
\text { Incorrect on first attempt }\end{array}$ \\
\hline \multicolumn{2}{|c|}{ 6) Correct orientation of M-CPR device? (e.g. facing towards the operator of } & $\begin{array}{l}\text { Correct at first attempt } \\
\text { Incorrect on first attempt }\end{array}$ \\
\hline \multicolumn{2}{|l|}{ 7) Press button ' 1 ' } & $\begin{array}{l}\text { Correct at first attempt } \\
\text { Incorrect on first attempt }\end{array}$ \\
\hline \multicolumn{2}{|c|}{ 8) Pull down suction cup } & $\begin{array}{l}\text { Correct at first attempt } \\
\text { Incorrect on first attempt }\end{array}$ \\
\hline \multicolumn{2}{|l|}{ 9) Press button ' 2 ' } & $\begin{array}{l}\text { Correct at first attempt } \\
\text { Incorrect on first attempt }\end{array}$ \\
\hline \multicolumn{2}{|l|}{ 10) Press button ' 3 ' } & $\begin{array}{l}\text { Correct at first attempt } \\
\text { Incorrect on first attempt }\end{array}$ \\
\hline \multicolumn{2}{|c|}{ 11) Place shoulder strap to prevent inadvertent migration of device? } & $\begin{array}{l}\text { Correct at first attempt } \\
\text { Incorrect on first attempt }\end{array}$ \\
\hline \multicolumn{2}{|c|}{ TOTAL NUMBER OF 'FIRST ATTEMPT' ERRORS } & TOTAL ERRORS $=$ \\
\hline
\end{tabular}

Figure 2 Data collection sheet and error list.

to 4 min. Feedback was semi-structured using a Gather-Analyse-Summarise framework and faculty referred to an M-CPR error checklist (figure 2). ${ }^{17}$

\section{Standardised intervention (4-month repeat simulation)}

The standardised intervention consisted of a brief 'skills refresher' after 4 months. ${ }^{17}$ The skills refresher consisted of a repeat of the standardised simulation with semi-structured feedback. Feedback was again limited to $4 \mathrm{~min}$ and delivered by trained simulation instructors (AC and NM). To avoid the risk of observer bias two independent investigators measured the outcomes at the 6-month assessments. The control group received no additional allocated simulation training but were exposed to routine M-CPR 'real-life exposure'. In order to assess equivalency of real-life exposure between groups, at the end of the study we asked all participants if they had used M-CPR in their everyday clinical practice over the 6 months.

\section{Outcome measures}

Time required to initiate $\mathrm{M}-\mathrm{CPR}$ was the primary outcome measure. This variable was considered a reasonable surrogate measure of M-CPR skill proficiency. The secondary outcome measure was a quantitative assessment against a checklist of important errors (figure 2). Assessment of critical errors that would be likely to cause 'ineffective' or 'unsafe' use of the device were determined by consensus of two investigators. 


\section{Randomisation, blinding and analysis}

Following baseline training, participant pairs were allocated at random to intervention or control groups. Simple randomisation was conducted using an electronic tool (www.graphpad. com/quickcalcs). Randomisation was conducted by the lead investigator with oversight by an independent statistician. ${ }^{16}$ The intervention and control groups were allocated to a training and assessment schedule within defined time windows scheduled by the lead investigator (figure 1). Following randomisation, all reasonable measures were taken to maintain allocation concealment. The final 6-month assessments were carried out by investigators who were blinded to the participants' group allocation.

Overall, 6/112 (5.4\%) of participants were lost to follow-up. Loss to follow-up was due to either planned leave or sick leave (figure 2). Additionally, an extreme outlying result in the intervention group was excluded from the final analysis. The outlying result was caused by an episode of inadvertent equipment failure during the 6-month assessment.

There was no 'crossover' of subjects from one treatment arm to the other. The baseline assessments of all 112 enrolled participants and of the 104 subjects who completed the 6-month assessment are included in the baseline characteristics results (table 2).

The data were analysed using IBM SPSS (V.24). A 5\% two-sided significance level was used throughout. Time to successful M-CPR application and the number of errors were not normally distributed variables. They are summarised by treatment using medians and IQRs (lower to upper quartile), and ranges (minimum to maximum). Mann-Whitney rank-sum tests are used to test for differences between groups at baseline and at 6 months. Box plots are used to illustrate the approximately normal distributions of within-subject changes in the outcomes from baseline to 6-month assessment by treatment. Means and 95\% CIs are used to summarise these within-subject changes. Paired t-tests are used to test for within-subject change separately for each treatment group.

\section{RESULTS}

Participants were enrolled during a 4-week baseline training window (table 1). Participants included 25 senior doctors (consultants), 21 doctors in training (registrars) and 66 registered nurses. The registered nurses included 20 from cardiology and 46 from the ED. Median postgraduate career experience was 8.5 years (range 1-36 years). Baseline characteristics of participants randomised to the intervention and control groups were similar. Self-reported 'real-life' clinical use of M-CPR devices during the study period was $36 / 54(66.7 \%)$ in the intervention group and $34 / 50(68.0 \%)$ in the control group $(\mathrm{p}=0.885)$.

The primary outcome (time taken to initiate M-CPR) is reported in table 2. At baseline, the intervention group had a median time to M-CPR initiation of 31.2s (IQR 25.9-39.0) compared with 26.5 (IQR 22.7-31.9) in controls. This represented an unexpected statistically significant imbalance at baseline $(p=0.006)$. At the 6-month assessment, the intervention and

Table 1 Participant baseline characteristics $(n=112)$

\begin{tabular}{lcc}
\hline & $\begin{array}{l}\text { Intervention } \\
\text { group }(\mathrm{n}=60)\end{array}$ & $\begin{array}{l}\text { Control group } \\
(\mathrm{n}=52)\end{array}$ \\
\hline Median years postqualification (range) & $8.5(3-36)$ & $8.5(1-25)$ \\
Basic life support and ALS trained $(\mathrm{n} / \%)$ & $60(100 \%)$ & $52(100 \%)$ \\
Consultant doctors $(\mathrm{n} / \%)$ & $16(26.7 \%)$ & $9(17.3 \%)$ \\
Registrar doctors $(\mathrm{n} / \%)$ & $10(16.7 \%)$ & $11(21.2 \%)$ \\
Registered nurses $(\mathrm{n} / \%)$ & $34(56.7 \%)$ & $32(61.6 \%)$ \\
\hline
\end{tabular}

Table 2 Time to initiation of mechanical cardiopulmonary resuscitation (M-CPR)

\begin{tabular}{|c|c|c|c|}
\hline & $\begin{array}{l}\text { Intervention } \\
\text { group }\end{array}$ & Control group & $P$ value \\
\hline $\begin{array}{l}\text { Baseline assessment: } \\
\text { median time to M-CPR } \\
\text { initiation in seconds } \\
\text { (IQR and range) }\end{array}$ & $\begin{array}{l}31.2 \\
(25.9-39.0) \\
(20-59 s) \\
(n=60)\end{array}$ & $\begin{array}{l}26.5 \\
(22.7-31.9) \\
(17-66 s) \\
(n=52)\end{array}$ & 0.006 \\
\hline $\begin{array}{l}\text { Baseline assessment*: } \\
\text { median time to M-CPR } \\
\text { initiation in seconds } \\
\text { (IQR and range) }\end{array}$ & $\begin{array}{l}31.5 \\
(25.9-39.0) \\
(20-59 s) \\
(n=54)\end{array}$ & $\begin{array}{l}26.5 \\
(22.7-31.9) \\
(17-66 \mathrm{~s}) \\
(n=50)\end{array}$ & 0.004 \\
\hline $\begin{array}{l}\text { Final (6 months) time to } \\
\text { initiate M-CPR: } \\
\text { median time to M-CPR } \\
\text { initiation in seconds } \\
\text { (IQR and range) }\end{array}$ & $\begin{array}{l}27.0 \\
(22.0-31.0) \\
(15-58 \mathrm{~s}) \\
(n=54)\end{array}$ & $\begin{array}{l}31.0 \\
(25.6-46.0) \\
(17-64 s) \\
(n=50)\end{array}$ & 0.003 \\
\hline $\begin{array}{l}\text { Change from baseline to } \\
\text { final: } \\
\text { change in time to M-CPR } \\
\text { initiation in seconds } \\
\text { (IQR and range) }\end{array}$ & $\begin{array}{l}-5.6 \\
(-14.0-1.2) \\
(-37-30.2 s) \\
(n=54)\end{array}$ & $\begin{array}{l}4.3 \\
(-2.4-19.0) \\
(-40.0-35.8 \mathrm{~s}) \\
(n=50)\end{array}$ & $\leq 0.001$ \\
\hline
\end{tabular}

*excludes participants lost to follow up at the final assessment.

control groups had a median time of $27.0 \mathrm{~s}$ (IQR 22.0-31.0) and $31.0 \mathrm{~s}$ (IQR 25.6-46.0), respectively. This difference in distribution between groups of the primary outcome at 6 months was statistically significant $(\mathrm{p}=0.003)$.

Box plots (figure 3 ) are presented to illustrate the within-subject change in time to initiation from baseline to 6 months by group. These within-subject changes demonstrate approximate normality. For those receiving the intervention, the average time to initiation decreased by $6.7 \mathrm{~s}(95 \% \mathrm{CI} 3.3$ to $10.0 \mathrm{~s}, \mathrm{p}<0.001)$. For controls, the average time increased by $5.1 \mathrm{~s}(95 \% \mathrm{CI} 0.3$ to $9.9 \mathrm{~s}, \mathrm{p}=0.036$ ). A general linear model was fitted to the 'time to M-CPR initiation at 6 months' to adjust for the baseline imbalance between groups. This model included the treatment factor (intervention vs control) and baseline time to initiation as a covariate. The estimated mean difference between the intervention and control groups in time to M-CPR initiation at 6 months after adjustment was $8.6 \mathrm{~s}(95 \% \mathrm{CI} 4.3$ to $12.8 \mathrm{~s}, \mathrm{p}<0.001)$.

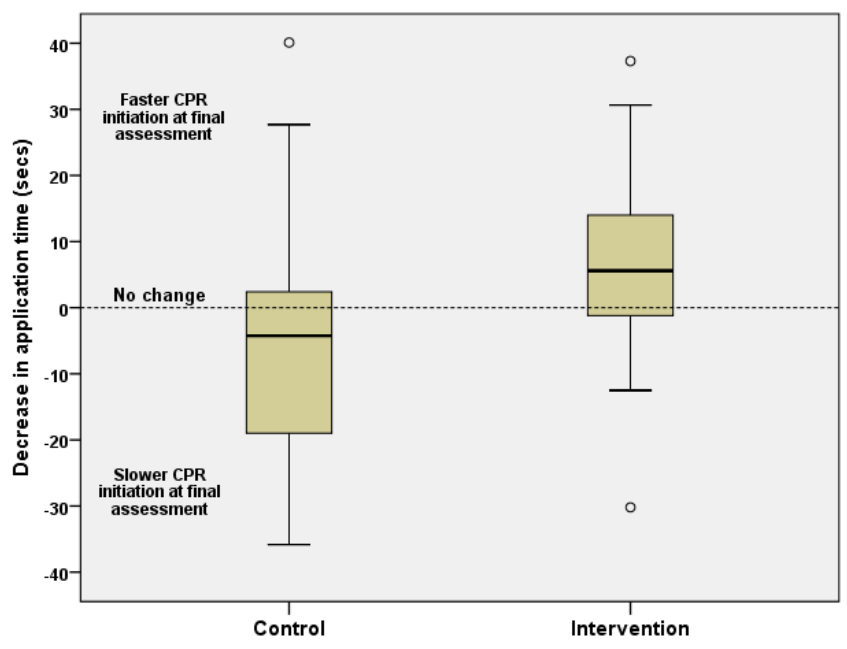

Figure 3 Time to initiation of mechanical cardiopulmonary resuscitation (M-CPR). 


\begin{tabular}{|c|c|c|c|}
\hline & $\begin{array}{l}\text { Intervention } \\
\text { group }\end{array}$ & $\begin{array}{l}\text { Control } \\
\text { group }\end{array}$ & $P$ value \\
\hline $\begin{array}{l}\text { Baseline assessment: } \\
\text { median number of errors (range) }\end{array}$ & $\begin{array}{l}\text { Two errors } \\
(0-5) \\
(n=60)\end{array}$ & $\begin{array}{l}\text { Two errors } \\
(0-4) \\
(n=52)\end{array}$ & 0.434 \\
\hline $\begin{array}{l}\text { Baseline assessment:* } \\
\text { median number of errors (range) }\end{array}$ & $\begin{array}{l}\text { Two errors } \\
(0-5) \\
(n=54)\end{array}$ & $\begin{array}{l}\text { Two errors } \\
(0-3) \\
(n=50)\end{array}$ & 0.397 \\
\hline $\begin{array}{l}\text { Final ( } 6 \text { months) assessment: } \\
\text { median number of errors (range) }\end{array}$ & $\begin{array}{l}\text { Two errors } \\
(0-4) \\
(n=54)\end{array}$ & $\begin{array}{l}\text { Three errors } \\
(0-5) \\
(n=50)\end{array}$ & $<0.001$ \\
\hline
\end{tabular}

*excludes participants lost to follow up at the final assessment.

The secondary outcome (occurrence of critical errors) is reported in table 3 . There was no significant difference in the rate of errors between groups at baseline $(p=0.434)$. At the 6-month assessment, the intervention group had a median error rate of 2 per scenario (IQR 1-3) compared with a median of 3 per scenario (IQR $2-3)$ in the control group $(\mathrm{p}<0.001)$. For the 104 subjects who completed the 6-month assessment, there was a statistically significant within-subject change in number of errors from baseline to 6 months $(p=0.007)$. Individual errors for the 104 subjects who completed the study were compared between baseline and 6 months. No statistically significant within-subject change in the number of errors was observed in the intervention group $(p=0.517)$. In the control group, the median within-subject increase in the number of errors was 1 (IQR $0-2$, $\mathrm{p}<0.001$ )

Table 4 provides a supplementary overview of the whole study cohort in terms of specific types of errors made. This table reports on the rate of each individual error at baseline and at 6 months. The change in error rate from baseline to 6 months reached statistical significance for error ' 6 ', ' 9 ' and ' 11 '.

\section{DISCUSSION}

M-CPR may have advantages over manual chest compressions in specific scenarios such as prolonged cardiac arrest and during transportation. ${ }^{18}$ Of note, a recent increase in the use of $\mathrm{M}$-CPR has occurred in various clinical settings. ${ }^{19}$ Despite an increase in uptake, M-CPR is unlikely to be used every day by
ALS providers. Therefore, if M-CPR is to be used a high level of baseline training and an approach to skill maintenance are both important considerations.

In this RCT of approaches to resuscitation training, we report that a brief simulation-based intervention at 4 months led to a reduction in the time to initiate $\mathrm{M}$-CPR at 6-month follow-up. At baseline, the measured time to initiate M-CPR was unexpectedly superior in controls (median 26.5 vs $31.2 \mathrm{~s})(\mathrm{p}=0.006$ ). While the high level of baseline performance is notable, by the study conclusion a reversal was observed, with a superior performance in the intervention group. The attrition of performance seen in controls is consistent with findings from other studies examining resuscitation skill maintenance. ${ }^{2021}$ The skill attrition observed is also in keeping with studies that show skills return to near baseline without retraining. ${ }^{13}$

In terms of effect size, for participants receiving the intervention, the average time to successful M-CPR application decreased from baseline to 6 months by $6.7 \mathrm{~s} \quad(95 \% \mathrm{CI} 3.3$ to $10.0 \mathrm{~s}, \mathrm{p}<0.001)$. For control subjects it increased by $5.1 \mathrm{~s}$ $(95 \% \mathrm{CI} 0.3$ to $9.9 \mathrm{~s}, \mathrm{p}=0.036)$. While these results represent a statistically significant change, the actual difference was relatively small (measured in seconds). Therefore, the results in themselves should not be viewed as either clinically significant or a justification for using M-CPR.

In terms of strengths, the study used standardised measures of performance and the educational intervention was brief and used in-kind resources. The study was randomised, blinded and accounted for confounders such as variance in the rate of clinical exposure to M-CPR (table 1). As a result, the findings represent a useful addition to previous observational studies examining M-CPR training. Moreover, the intervention was achievable with low-cost simulation equipment and a small amount of faculty time. An efficient use of faculty is especially important in busy ED settings where time constraints may limit training opportunities. In terms of applicability to a busy ED, the intervention was very brief $(10 \mathrm{~min})$ and structured (figure 2$)$. The training was completed in pairs, halving the required faculty time, and increasing opportunities for participants to improve their teamwork. In addition, the learning needs of experienced providers, such as communication skills and correction of errors, could be individually addressed with immediate feedback on performance.

Table 4 Categorisation of errors at baseline and 6-month assessments

\begin{tabular}{|c|c|c|c|c|c|c|c|}
\hline \multirow[b]{2}{*}{ Error checklist (figure 2) } & \multicolumn{3}{|c|}{ Baseline assessments $(n=56)$} & \multicolumn{3}{|c|}{ Final (6 months) assessments $(n=52)$} & \multirow[b]{2}{*}{$\begin{array}{l}\text { P value } \\
\text { (total errors) }\end{array}$} \\
\hline & $\begin{array}{l}\text { Intervention } \\
\text { group } \\
(n=30)\end{array}$ & $\begin{array}{l}\text { Control group } \\
(n=26)\end{array}$ & $\begin{array}{l}\text { Total baseline } \\
\text { errors } \\
(n=56)\end{array}$ & $\begin{array}{l}\text { Intervention } \\
\text { group } \\
(n=27)\end{array}$ & $\begin{array}{l}\text { Control group } \\
(\mathrm{n}=25)\end{array}$ & $\begin{array}{l}\text { Total final errors } \\
(\mathrm{n}=52)\end{array}$ & \\
\hline $\begin{array}{l}\text { (1) Failure to lift patient up to semi-sitting or failure to } \\
\text { log-roll? (n/\%) }\end{array}$ & $1(3.3 \%)$ & $0(0 \%)$ & $1(1.79 \%)$ & $1(3.70 \%)$ & $0(0 \%)$ & $1(1.92 \%)$ & 0.96 \\
\hline $\begin{array}{l}\text { (2) Failure to prevent risk of accidental removal of } \\
\text { endotracheal tube? }(\mathrm{n} / \%)\end{array}$ & $18(60 \%)$ & $10(38.46 \%)$ & $28(50.0 \%)$ & $9(33.33 \%)$ & $14(56.0 \%)$ & $23(44.23 \%)$ & 0.55 \\
\hline (3) Incorrect position of suction cup? (n/\%) & $6(20.0 \%)$ & $7(26.92 \%)$ & $13(23.21 \%)$ & $3(11.11 \%)$ & $5(20.0 \%)$ & $8(15.38 \%)$ & 0.31 \\
\hline (4) Failure to place arms outside device? (n/\%) & $0(0 \%)$ & $1(3.85 \%)$ & $1(1.79 \%)$ & $0(0 \%)$ & $0(0 \%)$ & $0(0 \%)$ & - \\
\hline (5) Device locked in correctly at first attempt? (n/\%) & $4(13.33 \%)$ & $5(19.23 \%)$ & $9(16.10 \%)$ & $3(11.1 \%)$ & $3(12.0 \%)$ & $6(11.54 \%)$ & 0.50 \\
\hline (6) Correct orientation of the M-CPR device? (n/\%) & $3(10.0 \%)$ & $2(7.69 \%)$ & $5(8.93 \%)$ & $5(18.52 \%)$ & $8(32 \%)$ & $13(25 \%)$ & 0.03 \\
\hline (7) Failure to press button ' 1 '? (n/\%) & $4(13.33 \%)$ & $4(15.38 \%)$ & $8(14.29 \%)$ & $5(18.52 \%)$ & $6(24.0 \%)$ & $11(21.15 \%)$ & 0.87 \\
\hline (8) Failure to pull down suction cup? (n/\%) & $5(16.67 \%)$ & $5(19.23)$ & $10(17.86 \%)$ & $6(22.22 \%)$ & $3(12.0 \%)$ & $9(17.30 \%)$ & 0.94 \\
\hline (9) Failure to press button ' 2 '? (n/\%) & $2(6.67 \%)$ & $3(11.54 \%)$ & $5(8.83 \%)$ & $4(14.81 \%)$ & $10(40 \%)$ & $14(26.92 \%)$ & 0.01 \\
\hline (10) Failure to press button '3'? (n/\%) & $0(0 \%)$ & $1(3.85 \%)$ & $1(1.79 \%)$ & $0(0 \%)$ & $1(4.0 \%)$ & $1(1.92 \%)$ & 0.96 \\
\hline $\begin{array}{l}\text { (11) Failure to place shoulder strap to prevent migration of } \\
\text { device? }(n / \%)\end{array}$ & $11(36.67 \%)$ & $3(11.54 \%)$ & $14(25.0 \%)$ & $10(37.04 \%)$ & $18(72.0 \%)$ & $28(53.85 \%)$ & 0.002 \\
\hline Total & 54 & 41 & 95 & 46 & 68 & 114 & - \\
\hline
\end{tabular}

M-CPR, mechanical cardiopulmonary resuscitation 
In terms of wider application, several concepts from the study could be extrapolated to other areas of resuscitation training. First, the results add weight to the wider evidence that new skills decline disconcertingly quickly. Moreover, it appears that our skills may decline faster than we are tested for continuous professional development (CPD) accreditation. Studies reviewing this issue concluded there is no good evidence supporting annual assessment of CPD competence. ${ }^{21} 22$ Of note, many of the wellknown mandatory CPD training programmes provide either no follow-up, or optional abbreviated training several years later.

While the need for regular training is often viewed as prohibitively expensive, the intervention described could be carried out by a small group of motivated resuscitation educators. By adopting a similar approach, the frequency of in-house ED refresher training could be increased. As well as maintaining new M-CPR skills, participants who undertake a 'regular refresher' (also widely known as spaced learning) could be given opportunities to apply their M-CPR skills within the context of the wider ALS algorithm, and therefore also revise other important cardiac arrest skills such as defibrillation and drug administration.

In regard to the cohort as a whole (table 4), we observed that three specific errors had a significant increase their occurrence over the study period. As a result, these individual errors were the subject of further evaluation and targeted training. The three errors were 'failure to place the shoulder strap', 'failure to press button 2' and 'incorrect orientation of the M-CPR device'. A failure to place the shoulder strap is important because it can lead to device migration causing iatrogenic injury. ${ }^{23}$ This error was identified as a latent safety threat and has led to further training provided at regular intervals. On the other hand, we concluded that omitting the step of pressing 'button 2 ' was unlikely to lead to unsafe M-CPR operation. ${ }^{16}$ Additionally, the observed increase in 'incorrect orientation of the $M-C P R$ device' could be an anomalous finding. Many of our ED providers appeared to adapt their practice through the course of the study as a result of clinical use. Following initial training, we observed providers operating both the defibrillator and the M-CPR device simultaneously. This approach requires the opposite orientation of the device to the one taught during baseline training and therefore may explain the change in error rate observed.

Our overall experience with M-CPR was positive. However, conducting the study has highlighted the potential pitfalls of introducing new resuscitation technologies. In particular, we believe there is a risk of distraction from other key ALS priorities such as early defibrillation. Distraction could be minimised by well-designed education and cognitive aids that clearly state $\mathrm{M}-\mathrm{CPR}$ indications and contraindications. In the ward setting, many well-meaning providers are now aware of the availability of M-CPR but remain untrained in its use. As a result, ED M-CPR devices are now problematically requested by inpatient teams, despite there being no clear indication for the use M-CPR. This issue is being managed by a programme of continuing education and dissemination of cognitive aids highlighting appropriate indications for M-CPR. From a wider hospital perspective, the recent adoption of advanced interventions such as ECMO-CPR are likely to require a concerted effort to increase the standard of ALS training. The approach to M-CPR training described could be a strategy for training our local ALS teams to the necessary standards required for providing high-quality CPR in this context. $^{1824}$

\section{Limitations and future directions}

This study reports on the performance of a limited number of providers working in a single institution, so caution must be used in extrapolating the results. The study was only partially blinded, and participants were aware they were being observed, which could have led to bias. A further caveat of note is that we have made no assessment of patient outcomes or cost benefits of M-CPR.

Resuscitation requires coordination of many simultaneous interventions in a challenging environment. This complexity may not have been fully accounted for in the simulations provided. In the future, additional research could investigate the effectiveness of simulation training over a longer period or examine the frequency required for refresher training. Resuscitation educators may also benefit from a further understanding of the relationship between mandatory courses such as advanced cardiac life support and postcourse follow-up training programmes. ${ }^{25}$

\section{CONCLUSIONS}

The results from this RCT of M-CPR training suggest that a refresher simulation 4 months following skill acquisition results in an improved time to initiate M-CPR. Furthermore, simulation combined with structured feedback may also be a useful targeted educational strategy for maintaining the performance of other resuscitation skills.

Contributors $A C, N M, K H, M M$ and $A S$ conceived and designed the study. $A C, C N, F A$ and $K B$ conducted the data analysis. All authors contributed to the implementation, data acquisition, manuscript preparation and subsequent revisions.

Funding The authors have not declared a specific grant for this research from any funding agency in the public, commercial or not-for-profit sectors.

Competing interests None declared.

Patient consent for publication Not required.

Ethics approval The study protocols were approved by the Westmead Hospital (HREC) Ethics Committee (2016).

Provenance and peer review Not commissioned; externally peer reviewed.

Data sharing statement Unpublished data are available by email request from the corresponding author.

\section{REFERENCES}

1 Williams ST, Sykes MC, Boon Lim P, et al. The 2015 advanced life support guidelines: a summary and evidence for the updates. Emerg Med J 2016;33:357-60.

2 Perkins GD, Brace-McDonnell SJ. OHCAO Project Group. The UK Out of Hospital Cardiac Arrest Outcome (OHCAO) project. BMJ Open 2015;5:e008736.

3 Rubertsson S, Lindgren E, Smekal D, et al. Mechanical chest compressions and simultaneous defibrillation vs conventional cardiopulmonary resuscitation in out-ofhospital cardiac arrest: the LINC randomized trial. JAMA 2014;311:53-61.

4 Wagner $\mathrm{H}$, Terkelsen $\mathrm{CJ}$, Friberg $\mathrm{H}$, et al. Cardiac arrest in the catheterisation laboratory: a 5-year experience of using mechanical chest compressions to facilitate PCI during prolonged resuscitation efforts. Resuscitation 2010;81:383-7.

5 Ewy GA, Zuercher M. Role of manual and mechanical chest compressions during resuscitation efforts throughout cardiac arrest. Future Cardio/ 2013;9:863-73.

6 Couper K, Smyth M, Perkins GD. Mechanical devices for chest compression: to use or not to use? Curr Opin Crit Care 2015;21:188-94.

7 Manders S, Geijsel FE. Alternating providers during continuous chest compressions for cardiac arrest: every minute or every two minutes? Resuscitation 2009;80:1015-8.

8 Hallstrom A, Rea TD, Sayre MR, et al. Manual chest compression vs use of an automated chest compression device during resuscitation following out-of-hospital cardiac arrest: a randomized trial. JAMA 2006;295:2620-8.

9 Ong ME, Annathurai A, Shahidah A, et al. Cardiopulmonary resuscitation interruptions with use of a load-distributing band device during emergency department cardiac arrest. Ann Emerg Med 2010;56:233-41.

10 Ong ME, Quah JL, Annathurai A, et al. Improving the quality of cardiopulmonary resuscitation by training dedicated cardiac arrest teams incorporating a mechanical load-distributing device at the emergency department. Resuscitation 2013;84:508-14 
$11 \mathrm{Mmh}$ L, Chan CN, Byt L, et al. Randomised controlled study to assess skill retention at 6 vs 12 months after simulation training in shoulder dystocia. BMJ Simulation and Technology Enhanced Learning 2017.

12 Jensen ML, Lippert F, Hesselfeldt $R$, et al. The significance of clinical experience on learning outcome from resuscitation training-a randomised controlled study. Resuscitation 2009;80:238-43.

13 Smith KK, Gilcreast D, Pierce K. Evaluation of staff's retention of ACLS and BLS skills. Resuscitation 2008;78:59-65.

14 nQuery Statistical Analysis Tool. www.statsols.com/nquery (Accessed 22 Nov 2018).

15 Prinzing A, Eichhorn S, Deutsch MA, et al. Cardiopulmonary resuscitation using electrically driven devices: a review. J Thorac Dis 2015;7:459-67.

16 Coggins A. LUCAS Simulation Study - Video and Data Collection (2017, August). 2017.

17 Cheng A, Rodgers DL, van der Jagt É, et al. Evolution of the Pediatric Advanced Life Support course: enhanced learning with a new debriefing tool and Web-based module for Pediatric Advanced Life Support instructors. Pediatr Crit Care Med 2012;13:589-95.

18 Stub D, Bernard S, Pellegrino V, et al. Refractory cardiac arrest treated with mechanical CPR, hypothermia, ECMO and early reperfusion (the CHEER trial). Resuscitation 2015;86:88-94.
19 Pietsch U, Lischke V, Pietsch C. Benefit of mechanical chest compression devices in mountain HEMS: lessons learned from 1 year of experience and evaluation. Air Med J 2014;33:299-301.

20 Semeraro F, Signore L, Cerchiari EL. Retention of CPR performance in anaesthetists. Resuscitation 2006;68:101-8.

21 Binkhorst M, Coopmans M, Draaisma JMT, et al. Retention of knowledge and skills in pediatric basic life support amongst pediatricians. Eur J Pediatr 2018;177:1089-99.

22 Allen JA, Currey J, Considine J. Annual resuscitation competency assessments: a review of the evidence. Aust Crit Care 2013;26:12-17.

23 Platenkamp M, Otterspoor LC. Complications of mechanical chest compression devices. Neth Heart J 2014;22:404-7.

24 Tonna JE, Johnson NJ, Greenwood J, et al. Practice characteristics of Emergency Department extracorporeal cardiopulmonary resuscitation (eCPR) programs in the United States: The current state of the art of Emergency Department extracorporeal membrane oxygenation (ED ECMO). Resuscitation 2016;107:38-46.

25 Coggins A, Desai M, Nguyen K, et al. Early acquisition of non-technical skills using a blended approach to simulation-based medical education. Adv Simul 2017;2:1-7. 